\title{
Early Observations on Optic Neuritis and Uhthoff's Sign
}

\author{
J.M.S. Pearce \\ Emeritus Consultant Neurologist, Department of Neurology, Hull Royal Infirmary, Hull, UK
}

\section{Key Words}

Optic neuritis · Uhthoff's sign • Edward Nettleship

\begin{abstract}
For much of the 19th century, even after the discovery of the ophthalmoscope, the diagnostic clinical signs and the identity of primary optic nerve disease were confused and inaccurate. Amongst many contributions aimed at clarifying this muddle, those of Wilhelm Uhthoff and Edward Nettleship were of outstanding importance and are outlined here.
\end{abstract}

Copyright $\odot 2010$ S. Karger AG, Basel

On the 11th November 1851, Helmholtz [1] first publicly announced his Augenspiegel (ophthalmoscope) at the Society for Scientific Medicine of Königsberg. It was quickly published. Before this invaluable diagnostic discovery ${ }^{1}$, optic neuritis was often mistaken for other ocular and especially retinal pathologies [2].

In 1823, George Frick (1793-1870) in the first American textbook of ophthalmology (1823) had described:

1 Helmholtz acknowledged that Brucke himself was but a hair's breadth away from the invention of the ophthalmoscope in 1847; and the English surgeon William Cumming had stated the idea of an instrument for 'detection of disease of the retina and posterior part of the eye', in 1846, as had Charles Babbage in 1847.

\section{KARGER}

Fax +41613061234 E-Mail karger@karger.ch www.karger.com
'A species of blindness which is produced by some immediate affection of the optic nerve or its expansion into the retina... it may take place suddenly or slowly and be transient, permanent or intermittent' $[3,4]$.

But before ophthalmoscopy, Frick was unable clearly to distinguish optic neuritis from uveitis, migraine, retinal detachment, and orbital disorders. Saunders [5], in 1821, described similar problems in differential diagnosis. Both Hughlings Jackson [6] (1835-1911), and Von Graefe [7] (1828-1870), the 'founder of ophthalmology', both enthusiastic users of the ophthalmoscope, provided good descriptive accounts, but these were not widely heeded. By 1871, Thomas Clifford Allbutt [8] (1836-1925) complained: 'The number of physicians who are working with the ophthalmoscope in England may, I believe, be counted upon the fingers of one hand'. And in this seminal text, he recognized the clinical features of optic neuritis and 'atrophic amaurosis' and the frequent confusion with ischemic optic neuropathy.

Edward Nettleship [9], ophthalmologist at St Thomas' Hospital, London, in the most comprehensive account in 1884, emphasised pain on ocular movement, disk appearances, the loss of colour vision and central visual field defects. He accurately characterised the features of optic neuritis by: 
'Failure of sight limited to one eye, often accompanied by neuralgic pain about the temple and orbit and by pain in moving the eye; many recover but permanent damage and even total blindness may ensue; there is at first little, sometimes no, ophthalmoscopic change, but the disc often becomes more or less atrophic in a few weeks... 'The defect in vision is often described at first as a "gauze" or a "yellow mist" or a "dark patch" or a "spot" which covers the object looked at and gives an unnatural colour, the hand looking, for example, as if covered by a brown glove.

In the 19th century, optic neuritis was used as a descriptive term for papilloedema. Its most common cause was widely said to be a brain tumour. It was also recognized as a discrete disease of the optic nerves [8], though its aetiology was often uncertain. After Nettleship's seminal description, Thomas Buzzard's major review of 1893 reported 5 patients with a history of disseminated sclerosis that had episodes of visual failure with recovery, consistent with optic neuritis [10]. But like the large 1897 series of 350 cases reported by Gunn [11], the causes and mechanism of optic neuritis remained controversial; syphilis was common though not necessarily the cause, and many instances were attributed to ill-defined infections, sinusitis, tobacco amblyopia, and hysteria.

Two physicians clarified the confusion: Edward Nettleship and Wilhelm Uhthoff. Until their studies, the importance of central visual scotomata and the phenomenon described by Uhthoff in 1890, were unrecognized in distinguishing optic demyelination from other intracranial and ocular disorders.

\section{Uhthoff's Sign}

Uhthoff in 1890, was a Privatdocent für Augenheilkunde in Berlin. He depicted in multiple sclerosis the transient blurring of central vision occurring with exercise that has become known as Uhthoff's sign. He described patients in whom exertion and fatigue caused a deterioration in vision. The vision of his patient XVIII after walking around the room deteriorated from $6 / 200$ and $1 / 6$ in the right and left eyes to $4 / 200$ and $14 / 200$, respectively. Uhthoff [12] reported:

'At last I have to mention a phenomenon which I have observed in four cases, in which bodily exercise with fatigue caused a marked worsening of vision' (fig. 1).

Uhthoff [13] explained both the physical signs and aetiologies of optic neuritis in a discussion at the British Medical Association's Ophthalmology section in 1904:

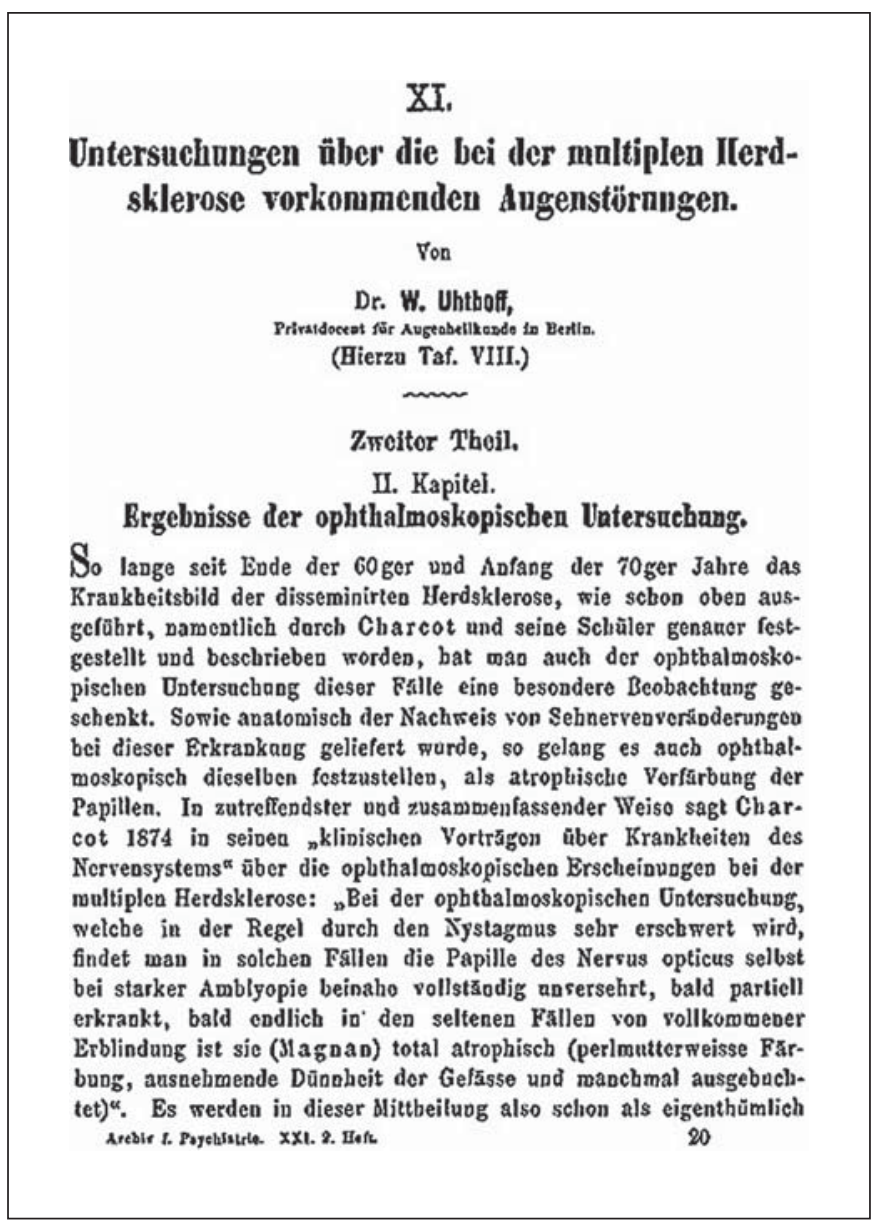

Fig. 1. Uhthoff's 'Untersuchungen über die bei der multiplen Herdsklerose vorkommenden Augenstörungen' 1890 [from Archiv für Psychiatrie und Nervenkrankheiten, Berlin, 1890].

'I think, too, that the form of the clinical disorders of vision in retrobulbar neuritis, their commencement and course, capacity for recovery, painfulness of movements of the eyeball in fresh cases, the tardy appearance of ophthalmoscopic phenomena after the vision has become affected, lack of characteristic central changes in the retina, absence of positive defects in the field of vision, etc., are symptoms which speak for a primary seat of the disturbance in the optic nerve. ...

'In more than half of the 120 cases I was unable to find the aetiological cause; where I did succeed in finding one, I diagnosed syphilis 14 times, hereditary tendency 11 times, disseminated sclerosis 6 times, anomalies of menstruation 5 times, pregnancy 6 times, decided effects of cold 5 times, acute loss of blood 3 times, disorders of the neighbouring cavities 3 times, periostitis orbitae 3 times, trauma twice, influenza twice, typhoid once, malaria once, polyneuritis once.'

Giving a detailed description of the optic papilla and visual fields, he concluded: 
'With the exception of cerebral tumours and tuberculous meningitis there is no disease of the nervous system (even including tabes) which is so often accompanied by ophthalmoscopic changes as disseminated sclerosis.'

While the phenomenon is particularly associated with a temporary worsening of optic neuritis, fatigue and sensory symptoms can also be worsened in some patients. Uhthoff's sign also has been recognized in other optic neuropathies, though it is most frequently associated with optic neuritis [14], affected patients having an increased risk of MRI abnormalities and of developing multiple sclerosis [15].

In a previously well young patient, the symptom is almost pathognomonic of optic neuritis. The usual history is of transient 'blurring or dark patches' in one or both central visual fields during exercise, in the hot shower or bath, recovering within a few minutes. The symptom evolution, and subsequent prognosis for overt multiple sclerosis are elaborated elsewhere $[16,17]$.

\section{Physiology of Uhthoff's Sign}

The sign suggests impaired but functioning myelin, which conducts electrical impulses more slowly when body temperature is elevated [18]; this led to the 'hot bath test' in the 1950s. A rise in temperature of $1.6^{\circ} \mathrm{C}$ retards central conduction time in pattern visual-evoked potentials (P2), in both normal subjects and in patients with demyelinated optic nerves [19]. However, exercise-induced Uhthoff's symptom is often accompanied by lesser or negligible rises in temperature [20], so that metabolic changes in axolemmal sodium flux and lactic acidosis may be more important than temperature change alone [21]. In the motor system, Uhthoff's phenomenon is due to varying conduction block associated with prolonged central motor conduction time (CMCT). In contrast to conduction block, CMCT is not importantly affected by temperature [22]. This arises because at the site of demyelination, the voltage-dependent sodium channels are more rapidly inactivated, resulting in a failure to generate nerve impulses [23, 24]. Conduction in unaffected parts of the axon is unimpaired [25]. In addition, segmental demyelination, even a modest widening of the nodal gap, can cause a conduction block. The partial restoration of conduction compensates for altered neural function related to the appearance of sodium channels along the demyelinated axolemma and the adoption of a more continuous (or micro-salutatory) mode of conduction [26, 27].

Optic Neuritis and Uhthoff's Sign

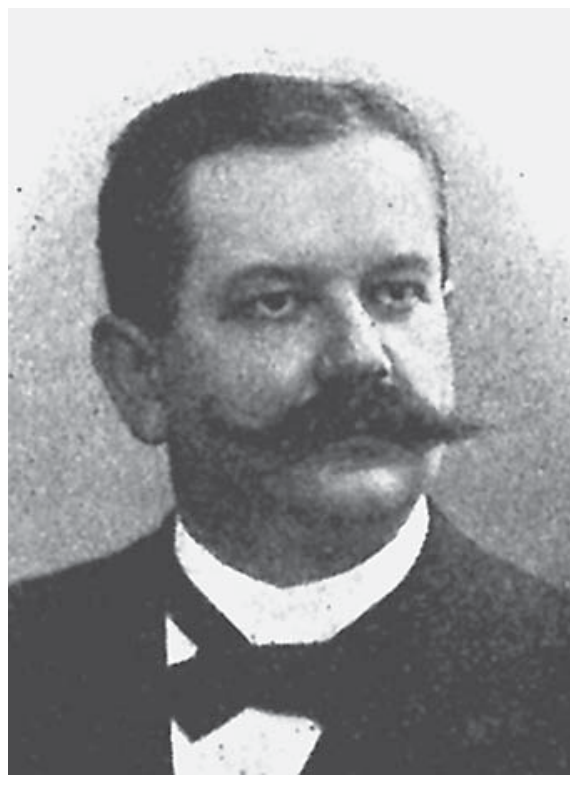

Fig. 2. Wilhelm Uhthoff.

\section{Wilhelm Uhthoff (1853-1927) (fig. 2)}

At the turn of the 20th century, the achievements of Wilhelm Uhthoff, a renowned German ophthalmologist heralded the beginning of contemporary neuro-ophthalmology. Uhthoff was born in Warin in the Grand Duchy of Mecklenburg-Schwerin. He began his studies in 1873, attending the universities of Tübingen, Göttingen, and Berlin. He received his doctorate at Berlin in 1877. He was assistant to Heinrich Leopold Schoeler (1844-1918) and was habilitated in Berlin. In 1890, Uhthoff went to Marburg as ordentlicher Professor, and in 1896 he succeeded C.F.R. Förster (1825-1902) at Breslau, until he retired in 1923. Bielschowsky described him as the true founder of clinical neuro-ophthalmology.

During World War I, Uhthoff related to Gordon Holmes his observations on the retinal connections to the cortex, based on his examining soldiers with shrapnel injuries to the brain. They suggested a detailed projection of the retina upon the cortex, the macula being represented in the calcarine region with successive radial zones along the borders of the fissures [28]. Uhthoff frequently presented papers and discussion at annual meetings of the British Medical Association's Ophthalmology section. And he published a Stereoscopischer ophthalmolog, several editions of the Handbuch der Augenheilkunde (Leipzig, Engelmann), and many papers including stud-

Eur Neurol 2010;63:243-247 
ies on cerebral thrombophlebitis, syphilis and conjunctivitis, and in 1915 he published a treatise in which he gave an early description of the disorder, which was to become known as the Foster Kennedy syndrome [29].

\section{Edward Nettleship (1845-1913) (fig. 3)}

Nettleship began his education at Kettering Grammar School and was then persuaded to train in agriculture and veterinary medicine before moving to medicine in which he qualified at the London Society of Apothecaries in 1867 . He quickly passed the FRCS in 1870 . Because of his childhood passion for bird watching he was nicknamed 'Bird-bearing Ned'. He worked in the London Hospital under Jonathan Hutchinson (1828-1913), whose interest in ophthalmology probably directed him to that discipline. He studied at Moorfields Eye Hospital, continued his association with Hutchinson and was a close friend of Waren Tay (1843-1927). The major part of his career was as an ophthalmic surgeon and lecturer at St Thomas' Hospital, where he remained from 1878 until 1895, and as surgeon at Moorfields from 1882 to 898 . He had a thriving private practice. His contemporaries described his extraordinarily scrupulously accurate observations and industry. This was especially applied to the genealogy of his patients with hereditary eye diseases, yielding important discoveries inter alia on the hereditary transmission of congenital night blindness [30]. After retirement he was elected a Fellow of the Roy-

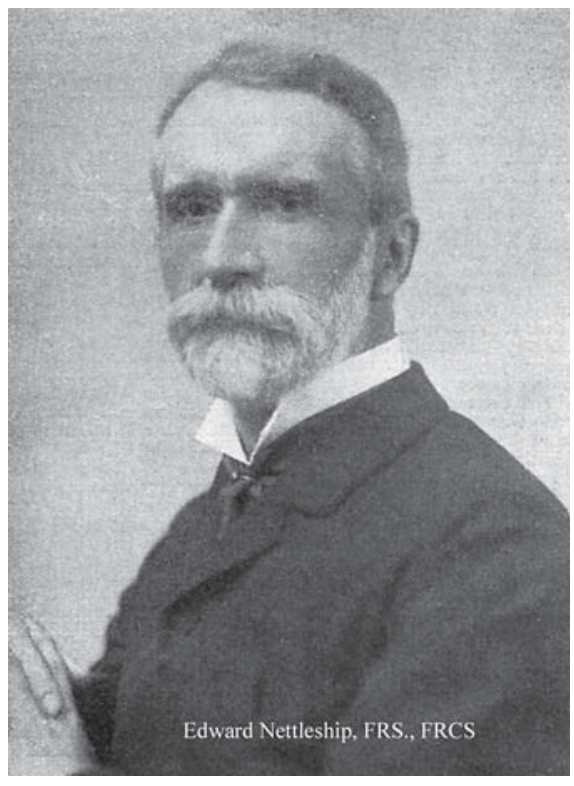

Fig. 3. Edward Nettleship [from Br Med J 1913;ii:1261-1263 (8 November), doi:10.1136/bmj.2.2758.1261].

al Society on 2 May 1912, proposed by Jonathan Hutchinson, Victor Horsley, David Ferrier, Hughlings Jackson and Henry Head. He contributed many papers on hereditary eye diseases, cataracts, toxic amblyopia, and colour blindness.

The Nettleship Medal of the Ophthalmological Society honoured his work.

\section{References}

1 Helmholtz H: Beschreibung eines AugenSpiegels. Berlin, Förstner'sche Verlagsbuchhandlung, 1851.

$\checkmark 2$ Pearce JMS: The Ophthalmoscope: Helmholtz's Augenspiegel. Eur Neurol 2009;61: 244-249.

3 Frick G: A Treatise on the Diseases of the Eye. Baltimore, Fielding Lucas, 1823.

4 Volpe NJ: Optic neuritis: historical aspects. J Neurophthalmol 2001;21:302-309.

5 Saunders JC: A Treatise on Some Practical Points Relating to Diseases of the Eye. Philadelphia, Benjamin Warner, 1821.

6 Jackson JH: A case of double optic neuritis without cerebral tumour. Royal London Ophthalmic Hospital Reports 1876;8:445455. See also Jackson JH: Discussion on the relation between optic neuritis and intracranial disease. Trans Ophthalmol Soc UK 1880-1881;1:60-115.
7 Von Graefe FWEA: Über Complicationen von Sehnervenentzündung. Graefe's Arch Ophthal 1860;7,2 Abt:58-71.

8 Allbutt TC: On the Use of the Ophthalmoscope in Diseases of the Nervous System and of the Kidneys. London, Macmillan, 1871, pp 63-64, 75 .

9 Nettleship E: On cases of retro-ocular neuritis. Trans Ophthal Soc UK 1884;4:186-226.

10 Buzzard T: Atrophy of the optic nerve as a symptom of chronic disease of the central nervous system. Br Med J 1893;ii:779-784.

11 Gunn RM: Discussion on retro-ocular neuritis. Trans Ophthal Soc UK 1897;17:107217.

12 Uhthoff W: Untersuchungen über die bei der multiplen Herdsklerose vorkommenden Augenstörungen. Arch Psychiatr Nervenkrankh 1890;21:55-116, 303-410.
13 Uhthoff W: Discussion on retro-ocular neuritis. Section of ophthalmology. Part iii. Br Med J 1904;ii:1285-1286.

14 Uhthoff W: Ophthalmic experiences and consideration on the surgery of cerebral tumours and tower skull. Trans Ophthal Soc UK 1914:34:47-123.

15 Scholl GB, Song HS, Wray SH: Uhthoff's symptom in optic neuritis: relationship to magnetic resonance imaging and development of multiple sclerosis. Ann Neurol 1991; 30:180-184.

16 Korsholm K, Madsen KH, Frederiksen JL, Skimminge A, Lund TE: Recovery from optic neuritis: an ROI-based analysis of LGN and visual cortical areas. Brain 2007;130: 1244-1253.

17 McDonald WI: Relapse, remission, and progression in multiple sclerosis. N Engl J Med 2000;343:1486-1487. 
$\checkmark 18$ Raminsky M: The effects of temperature on conduction in single demyelinated nerve fibres. Arch Neurol 1973;28:287-292.

19 Saul RF, Hayat G, Selhorst JB: Visual evoked potentials during hyperthermia, J Neuroophthalmol 1995;15:63-69.

20 Guthrie TC, Nelson DA: Influence of temperature changes on multiple sclerosis: critical review of mechanisms and research potential. J Neurol Sci 1995;129:1-8.

21 Selhorst JB, Saul RF. Uhthoff and his symptom. J Neuro-ophthalmol 1995; 15:63-69.

-22 Humm AM, Beer S, Kool J, Magistris MR, Kesselring J, Rosler KM: Quantification of Uhthoff's phenomenon in multiple sclerosis: a magnetic stimulation study. Clin Neurophysiol 2004;115:2493-2501.
23 Saul RF, Hayat G, Selhorst JB: Visual evoked potentials during hyperthermia J Neuroophthalmol 1995;15:70-78.

24 Craner MJ, Lo AC, Black JA, Waxman SG: Abnormal sodium channel distribution in optic nerve axons in a model of inflammatory demyelination. Brain 2003;126:15521561.

25 Waxman SG: Prerequisites for conduction in demyelinated fibers. Neurology 1978;28:2733.

$26 \mathrm{Wu}$ JV, Shrager P: Resolving three types of chloride channels in demyelinated Xenopus axons. J Neurosci Res 1994;38:613-620.

27 Waxman SG, Brill MH: Conduction through demyelinated plaques in multiple sclerosis: computer simulations of facilitation by short internodes. J Neurol Neurosurg Psychiatry 1978;41:408-416.

28 Holmes G, Lister WT: Disturbances of vision from cerebral lesions with special reference to the macula. Brain 1916;39:34-73.

29 Uhthoff W: Augensymptome bei Grosshirntumoren. Handb Augenheilk 1915;i:1143.

30 Obituary: Edward Nettleship. Br Med J I913;ii:1261-1263. 